\title{
Natural sources of internal category structure: Typicality, familiarity, and similarity of birds
}

\author{
JAMES S. BOSTER \\ University of Pittsburgh, Pittsburgh, Pennsylvania
}

\begin{abstract}
Typicality ratings of 53 types of birds by University of California, Berkeley undergraduates (Rosch, 1975b) were more strongly correlated with the number of related species than with the frequency of the birds in the observers' immediate environment or with the frequency of mention of the birds in written materials. Furthermore, the subjects made finer discriminations among the most typical birds (passerines) than among the less typical birds (nonpasserines), yet disagreed more often in identifying passerines and reported greater difficulty in judging the similarities among passerines. A single model explains both sets of results: passerines appear to be densely and continuously spread through the bird similarity space, whereas nonpasserines are more sparsely and discontinuously distributed, leading to the choice of passerines as both more typical and more difficult to categorize than nonpasserines.
\end{abstract}

There is an ample literature documenting that many categories have a graded internal structure such that some members of the category are regarded as more representative or "typical" of the category than are other members. For example, chairs are considered better examples of furniture than are rugs, and robins are judged better examples of birds than are penguins. These typicality judgments can be reliably elicited from subjects in a variety of semantic domains (Rosch, 1973, 1975b). Furthermore, variation in the typicality of category members affects a number of psychological variables, including reaction time (RT) in category verification tasks (McFarland, Duncan, \& Kellas, 1978; Rips, Shoben, \& Smith, 1973; Rosch, 1973; Smith, Shoben, \& Rips, 1974), order and probability of production of items (Mervis, Catlin, \& Rosch, 1976; Rosch, 1973, 1975b), acceptance of linguistic hedges (Lakoff, 1973), asymmetry of similarity judgments (Rosch, 1975a; Tversky \& Gati, 1978), and induction (Rips, 1975). Thus the graded structure of categories has profound implications for our understanding of classification and semantic memory (McFarland et al., 1978; Mervis \& Rosch, 1981; Rosch, 1973, 1978).

\section{Objectives}

Although investigators agree about the importance of typicality, they do not concur on its explanation. As discussed below, typicality judgments have been explained as based on the pattern of resemblances among category members (Rosch \& Mervis, 1975) and, alternatively, in terms of subjects' familiarity with category members

\footnotetext{
Research support was provided by an Andrew Mellon postdoctoral fellowship at the University of Pittsburgh. I am grateful to Mary Boster for help in locating data sources; to Roy D'Andrade, Cynthia Gaulin, Steven Gaulin, Carolyn Mervis, Emilie Roth, Allison Thompson, and two anonymous reviewers for comments; and to Brent Berlin and John $O$ 'Neill for their past and future collaboration. Any errors are my own. Address reprint requests to James S. Boster, Department of Anthropology, University of Pittsburgh, Pittsburgh, PA 15260.
}

(e.g., Ashcraft, 1978). The first objective of this study was to evaluate which account best explains typicality judgments in a single domain, that of birds. Furthermore, since typicality effects are related to many aspects of perception and the organization of semantic memory, an account of typicality should also explain other aspects of subjects' responses to category members. The second objective was to explore the relationship between typicality judgments and subjects' patterns of discrimination and identification of bird specimens. The first and second objectives were addressed in Experiments 1 and 2, respectively.

\section{Family Resemblance}

Rosch and Mervis (1975) interpreted typicality judgments as responses to the pattern of family resemblances among category members: the best examples of categories should be those that are most like other category members. Rosch and Mervis showed that the most typical members of six natural categories (furniture, vehicles, fruit, weapons, vegetables, and clothing) shared more attributes with other members of the category than did the least typical members (cf. Malt \& Smith, 1984; Roth \& Mervis, 1983). In a striking series of experiments, Rosch, Simpson, and Miller (1976) created artificial stimuli that elicited the same sorts of typicality effects that had previously been demonstrated for natural categories. Whether typicality is defined as likeness in configuration to a prototype (dot patterns), closeness in means of attributes (stick figures), or degree of family resemblance to other members (letter strings), the structurally most typical stimuli were most easily learned, most readily classified after learning, most often rated as typical, and first generated in a production task.

\section{Familiarity}

Later work challenged the generality of Rosch and Mervis's (1975) claims, arguing that the familiarity of items 
has an important, if not predominant, role in determining their typicality. Ashcraft (1978) showed that the average number of properties attributed to a category member (NP) was the best predictor of rated typicality $(r=.45)$ of those he examined. He suggested that the amount of information available about an item may be the underlying determinant of both faster RT and higher typicality. Similarly, McCloskey (1980) showed that familiarity of stimulus items is a confounding variable in many investigations of semantic memory. For example, he found that the correlation between typicality and RT is reduced from -.46 to -.37 when rated familiarity is partialled out.

Other authors argued that familiarity plays a subsidiary role in influencing typicality judgments. Glass and Meany (1978) showed that there are two types of atypical category members: familiar high-imagery instances (e.g., penguins) and unfamiliar low-imagery instances (e.g., grackles). They found that unfamiliar atypical items have faster RTs than familiar atypical items, indicating that familiarity is not the only determinant of RT. Malt and Smith (1982) showed that part of the reason for Ashcraft's (1978) result was a response bias to assign low typicality ratings to unfamiliar words. They, like Hampton and Gardiner (1983), concluded that familiarity is not the crucial variable in determining typicality. Finally, Schwanenflugel and Rey (1986) criticized the methods used to elicit properties of items in Ashcraft's experiments. Because Ashcraft's subjects listed properties of a large number of instances of categories, they were more likely to be reminded of the properties of typical items than they were to be reminded of the properties of atypical items. This can be considered a typicality confound in the measurement of NP. Schwanenflugel and Rey (1986) cited supporting evidence that the difference in property number disappears when subjects describe only one item from each category (Rosch \& Mervis, 1975). However, they found that when they controlled for familiarity, the correlation between typicality ratings of birds from culturally different subject groups improved from .16 to .57 . They concluded that familiarity is at least one influence on cultural differences in category typicality ratings.

In sum, subjects apparently do have a response bias to describe unfamiliar category items as atypical, using the heuristic "If I don't know about it, it must be weird." Nevertheless, familiarity is not the only determinant of typicality; some highly familiar items are required as atypical of their superordinate class (e.g., chicken, duck, seagull).

An illustration of this response bias is provided by the term titmouse. Rosch's (1975b) subjects rated it as one of the three least typical birds (along with penguin and $e m u)$. The term refers to relatives of the chickadee: small unremarkable passerines (songbirds) that look and behave very much like other typical birds (e.g., wrens, sparrows). However, Hampton (1979) found that his subjects barely included it in the bird category because many of them thought titmouse was a kind of mouse; they simply did not know what the word meant. Hampton's subjects judged titmouse atypical because the label was unfamiliar, even though the referent resembles typical birds. This case highlights the importance of distinguishing between labels and referents in eliciting judgments of familiarity and typicality (see also Malt \& Smith, 1982, pp. 69-70).

\section{Typicality Confounds in Familiarity Judgments}

Although there has been much discussion of familiarity confounds in ratings of typicality, I believe there should be more attention to the possibility of typicality confounds in judgments of familiarity. As mentioned above, Schwanenflugel and Rey (1986) described one possible confound in their critique of Ashcraft's (1978) procedures for measuring NP. Barsalou (1985) provided another such example. He argued that although central tendency or family resemblance predicts typicality in taxonomic categories (e.g., birds, furniture, vehicles), it does not predict typicality in goal-derived categories (e.g., foods not to eat on a diet, things to take from one's home during a fire, camping equipment). In contrast, he found that an item's similarity to ideals associated with category goals and an item's frequency of instantiation predict typicality in both types of category. Although I accept Barsalou's conclusion that graded structures reflect people's dynamic ability to construct categories, I believe his demonstration of it is circular: he measured frequency of instantiation by asking subjects to judge how often they encounter particular items as instances of superordinate categories. However, Tversky and Kahnemann (1974) showed that subjects often use a simplifying heuristic, such as the availability of the item in memory, to make difficult judgments of the frequency of a class. The most likely explanation of why frequency of instantiation judgments should be correlated with typicality is that subjects use their judgments of typicality as a simplifying heuristic for guessing how often they have encountered a particular item as an instance of a category.

A similar typicality confound may affect ratings of familiarity as well. McCloskey (1980) argued that log word frequency is not a good proxy for familiarity, since the correlation between rated familiarity and $\log$ word frequency is only . 33 and the correlation of rated familiarity and RT is unchanged when log word frequency is partialled out. This result has been similarly interpreted by other authors (e.g., Schwanenflugel \& Rey, 1986, p. 151). However, I believe another interpretation is possible. Log word frequency is a measure of the frequency of the item in the written environment, whereas rated familiarity is a measure of the subjects' evaluation of their knowledge of the item. It may be that the typicality of the item determines whether it will be remembered and judged as familiar, leading to a low correlation between rated familiarity and log word frequency and a high correlation between rated familiarity and rated typicality. In other words, one may expect that if individuals have equal exposure to two species of birds, they would judge the species that was more similar to other birds as the more 
familiar, for indeed, they would have seen more birds resembling the typical bird than the atypical one. Schustack and Anderson (1979) offered support for this interpretation by showing that providing subjects with good analogies to prior knowledge improves their memory for new instances. As mentioned above, Rosch et al. (1976) showed that, for artificial stimuli, the items most similar to other items are most readily learned. These results suggest that novel items similar to category prototypes would be regarded as more familiar than novel atypical items because they would be more memorable.

Part of the problem is deciding what we mean by "familiarity." If we mean subjective judgments of the frequency of exposure to an item, then, by definition, rated familiarity is the best measure. However, if we intend familiarity to refer to an individual's opportunities to learn about items, then objective measures of the items' label and referent frequencies would be preferred since they are less likely to be confounded with typicality. In this paper, I use the second meaning of familiarity.

To review, Experiment 1 evaluated whether familiarity or family resemblance best explains typicality judgments of birds, using measures that are unlikely to be subject to typicality confounds. Experiment 2 explored the relationship between typicality judgments and subjects' patterns of discrimination and identification of bird specimens.

\section{EXPERIMENT 1}

Experiment 1 addressed three problems suggested by the above review of the typicality literature. The first was the need for an explanation of typicality effects in natural categories, comparable to what Rosch et al. (1976) achieved for artificial categories. With natural stimuli, one cannot freely manipulate the degree of sharing of attributes as one can with artificial stimuli. However, since scientific taxonomy represents an attempt to capture the objective pattern of similarity among organisms, scientific species can be expected to share attributes with other members of the same biological order or family. ${ }^{1}$ Species in large orders or families are likely to share attributes with a larger number of other species than are species in small orders or families. Thus, the total number of species in the order or family of an item can serve as a proxy for Rosch and Mervis's (1975) notion of family resemblance, given the strong correspondence between folk and scientific biological classifications (Berlin, 1973; Berlin, Breedlove, \& Raven, 1973; Boster, 1987; Boster, Berlin, \& O'Neill, 1986; Diamond, 1966; Hunn, 1975). The second problem was the need to distinguish between labels and the referents themselves in gauging typicality and familiarity effects. The third problem was the need for explanatory variables that are not derived from the subjects' subjective judgments, in order to avoid circularity in the explanation of typicality.

In addressing these problems, this experiment evaluated three possible explanations of why some members of categories are judged to be better examples than others: label frequency, token frequency, and type frequency. The first two possible explanations represent accounts of typicality in terms of the familiarity of the items; the third explanation represents an account in terms of internal category structure, as originally proposed by Rosch and Mervis (1975). The label frequency explanation asserts that typicality ratings reflect frequency of exposure to item labels; one will judge an item to be typical if one hears its name frequently. Preliminary research indicates that this explanation is not supported: Mervis et al. (1976) have shown that typicality judgments are not related to word frequency as determined by the Kučra and Francis (1967) analysis of American English. The second possible explanation is that typicality reflects frequency of exposure to item tokens; one will judge an item to be typical if one encounters it frequently. This possibility has not been evaluated with natural items; it has been tested with artificial stimuli, and was found to have a moderate association with typicality judgments (Rosch et al., 1976). The third possible explanation is that typicality reflects the pattern of similarity among items; typical items are those that are similar to large numbers of other items (Rosch \& Mervis, 1975).

In this experiment, these alternative explanations of typicality were evaluated with respect to the category bird. This category was chosen for several reasons. First, it is probably the most frequently cited example of a category whose members vary in their typicality. Second, although many of the domains studied by Rosch (1975b) were natural kinds (vegetable, fruit, bird), only the category bird corresponds to a scientific taxon, the class Aves. This correspondence makes it possible to use scientific taxonomy to examine the basis of the typicality effect in this case. Finally, typicality judgments of birds can be placed in the context of other aspects of subjects' responses to the stimuli, including patterns of subjects' discrimination and identification of specimens. This is discussed in Experiment 2.

\section{Method}

I compared four sets of measures: typicality, label frequency, token frequency, and type frequency. Typicality norms for 53 items in the category bird were taken from Rosch (1975b, p. 232). Rosch elicited judgments from 209 students in three undergraduate psychology classes at the University of California, Berkeley. She asked each student to rate on a 7-point scale "the extent to which each instance represented their idea or image of the meaning of the category term" (1975b, p. 198). The least typical example of the category bird in Rosch's (1975b) stimulus set, the item bat, was eliminated from consideration in this analysis because it is not a member of the scientific taxon Aves.

Label frequency was determined for each of the items by use of the Kucera and Francis (1967) compilation of more than one million words from 500 samples of American English, adding together the frequency of singulars and plurals. Entries for gull were summed with the entries for seagull, and entries for jay were summed with the entries for bluejay. Use of this variable replicates the analysis presented by Mervis et al. (1976), with the difference that they included possessive forms in their use of the same materials. 
Token frequency was determined for each of the birds through use of the National Audubon Society's (1983) Christmas bird counts for communities in the San Francisco Bay Area surrounding the site of Rosch's (1975b) Berkeley study, including Contra Costa County, Oakland, Hayward-Fremont, Southern Marin County, and Palo Alto (pp. 749-767). The Audubon Christmas bird count represents a nationwide attempt to estimate the size of overwintering bird populations. On the day of the count, small parties of observers record all the birds they see within the circles of territory they are responsible for. In the Bay Area, 418 observers in 180 parties spent a total of 1,437 party-hours and covered a total of 2,732 miles, an average of $8 \mathrm{~h}$ and 15 miles per party. Another $36 \mathrm{ob}-$ servers watched at feeders. Altogether, they recorded $1,489,458$ birds, representing more than 180 distinct species.

Type frequency was operationalized in three distinct ways. The first, abstract type frequency (ATF), attempts to capture the abstract similarity of the bird to all other birds independently of the subjects' interactions with them. This was determined by counting the number of species in the same scientific order and family worldwide (Wallace \& Mahan, 1975, pp. 40-55). These measures are referred to as order ATF and family ATF. The scientific classification of the birds is presented in Table 1. It was necessary to use world counts because many of the birds in Rosch's (1975b) set do not occur naturally in the United States (e.g., ostriches and penguins).

As a variant of this operationalization, the average taxonomic distance (Boster, 1987; Boster et al., 1986) of each bird from all other birds was also computed. The taxonomic distance between a pair of species is measured by counting the nodes one has to ascend in the scientific taxonomic tree to arrive at a node that includes both scientific species. Thus different species in the same genus have a taxonomic distance of 1 , different genera in the same family have a taxonomic distance of 2 , and different families in the same order have a taxonomic distance of 3 . Thus, for any bird, the average taxonomic distance to other birds is equal to

$$
\frac{3 N+2-O-F}{N},
$$

where $N$ is the total number of bird species minus one, $O$ is the number of species in the bird's scientific order, and $F$ is the number of species in the bird's scientific family (distinctions within the family are ignored here). This measure is referred to as average relatedness.

The second operationalization, experiential type frequency (ETF), attempts to capture the subjects' frequency of exposure to similar types. This measure is a hybrid of type and token frequency; it allows one to test whether subjects judge an item to be typical if they encounter like items frequently. It was determined by summing the total number of individual birds in the same order and family as a target bird across all the birds encountered in the Bay Area 1983 Christmas bird counts. These measures are referred to as order ETF and family ETF.

The third operationalization, conceptual type frequency (CTF), attempts to capture the similarity of the bird to the other birds familiar to the subjects. This measure allows one to test whether subjects judge an item to be typical if it is similar to other items they know about. The birds listed in the Battig and Montague (1969) category norms were used as the universe of familiar

Table 1

Scientific Classification of Birds

\begin{tabular}{|c|c|c|}
\hline Order & Family & Common Names \\
\hline Sphenisciformes & Spheniscidae & penguin \\
\hline Struthioniformes & Struthionidae & ostrich \\
\hline Casuariiformes & Dromiceidae & emu \\
\hline Procellariiformes & Diomedeidae & albatross \\
\hline Pelecaniformes & Pelecanidae & pelican \\
\hline Ciconiiformes & Ardeidae & egret \\
\hline Ciconiiformes & Ciconiidae & stork \\
\hline Ciconiiformes & Phoenicopteridae & flamingo \\
\hline Anseriformes & Anatidae & swan, goose, duck \\
\hline Falconiformes & Cathartidae & condor, vulture \\
\hline Falconiformes & Accipitridae & eagle, hawk, buzzard \\
\hline Falconiformes & Falconidae & falcon \\
\hline Galliformes & Phasianidae & pheasant, chicken, peacock \\
\hline Galliformes & Meleagrididae & turkey \\
\hline Gruiformes & Gruidae & crane \\
\hline Charadriiformes & Scopacidae & sandpiper \\
\hline Charadriiformes & Laridae & seagull \\
\hline Columbiformes & Columbidae & pigeon, dove \\
\hline Psittaciformes & Psittacidae & parrot, parakeet \\
\hline Strigiformes & Strigidae & owl \\
\hline Apodiformes & Trochilidae & hummingbird \\
\hline Piciformes & Ramphastidae & toucan \\
\hline Piciformes & Picidae & woodpecker \\
\hline Passeriformes & Alaudidae & lark \\
\hline Passeriformes & Hirundinidae & swallow \\
\hline Passeriformes & Corvidae & bluejay, raven, crow \\
\hline Passeriformes & Paridae & titmouse \\
\hline Passeriformes & Troglodytidae & wren \\
\hline Passeriformes & Mimidae & catbird, mockingbird \\
\hline Passeriformes & Turdidae & robin, thrush, bluebird \\
\hline Passeriformes & Sturnidae & starling \\
\hline Passeriformes & Icteridae & blackbird, oriole \\
\hline Passeriformes & Fringillidae & $\begin{array}{l}\text { redbird, cardinal, finch, } \\
\text { goldfinch, canary, sparrow }\end{array}$ \\
\hline
\end{tabular}

Note-The classification follows that presented by Wallace and Mahan (1975). 
birds. These category norms were generated by giving 442 subjects a category name or description and asking them to write down as many category members as they could think of in a 30-sec period. The measures of CTF were determined by summing the total number of individual birds in the same order and family as a target bird across all the birds listed in the Battig and Montague (1969) norms. These measures are referred to as order CTF and family CTF.

In the correlations and multiple regressions presented below, all frequency variables have been transformed to started logs,

Table 2

Typicality, Label, Token, and Type Frequencies of 53 Birds

\begin{tabular}{|c|c|c|c|c|c|c|c|c|c|c|c|}
\hline Common Name & $\begin{array}{c}\text { Order } \\
\text { Name* }\end{array}$ & Typicality & $\begin{array}{c}\text { Label } \\
\text { Frequency }\end{array}$ & $\begin{array}{c}\text { Token } \\
\text { Frequency }\end{array}$ & $\begin{array}{c}\text { Order } \\
\text { ATF }\end{array}$ & $\begin{array}{c}\text { Family } \\
\text { ATF }\end{array}$ & $\begin{array}{c}\text { Average } \\
\text { Relatedness }\end{array}$ & $\begin{array}{c}\text { Order } \\
\text { ETF }\end{array}$ & $\begin{array}{c}\text { Family } \\
\text { ETF }\end{array}$ & $\begin{array}{l}\text { Order } \\
\text { CTF }\end{array}$ & $\begin{array}{c}\text { Family } \\
\text { CTF }\end{array}$ \\
\hline robin & PASS & 1.02 & 2 & 3,902 & 5,037 & 305 & 2.334 & 106,632 & 5,126 & 36 & 4 \\
\hline sparrow & PASS & 1.18 & 0 & 17,685 & 5,037 & 425 & 2.319 & 106,632 & 31,788 & 36 & 8 \\
\hline bluejay & PASS & 1.29 & 15 & 3,217 & 5,037 & 100 & 2.360 & 106,632 & 4,341 & 36 & 3 \\
\hline bluebird & PASS & 1.31 & 1 & 623 & 5,037 & 305 & 2.334 & 106,632 & 5,126 & 36 & 4 \\
\hline canary & PASS & 1.42 & 0 & 0 & 5,037 & 425 & 2.319 & 106,632 & 0 & 36 & 8 \\
\hline blackbird & PASS & 1.43 & 1 & 24,842 & 5,037 & 88 & 2.361 & 106,632 & 27,912 & 36 & 7 \\
\hline dove & COLU & 1.46 & 5 & 3,536 & 305 & 289 & 2.926 & 10,154 & 10,154 & 3 & 3 \\
\hline lark & PASS & 1.47 & 4 & 84 & 5,037 & 75 & 2.363 & 106,632 & 84 & 36 & 1 \\
\hline swallow & PASS & 1.52 & 12 & 215 & 5,037 & 75 & 2.363 & 106,632 & 215 & 36 & 2 \\
\hline parakeet & PSIT & 1.53 & 1 & 0 & 315 & 315 & 2.922 & 0 & 0 & 3 & 3 \\
\hline oriole & PASS & 1.61 & 16 & 1 & 5,037 & 88 & 2.361 & 106,632 & 0 & 36 & 7 \\
\hline mockingbird & PASS & 1.62 & 0 & 260 & 5,037 & 30 & 2.368 & 106,632 & 357 & 36 & 2 \\
\hline wren & PASS & 1.64 & 0 & 768 & 5,037 & 63 & 2.364 & 106,632 & 768 & 36 & 1 \\
\hline redbird & PASS & 1.64 & 3 & 0 & 5,037 & 425 & 2.319 & 106,632 & 0 & 36 & 8 \\
\hline finch & PASS & 1.66 & 0 & 7,593 & 5,037 & 425 & 2.319 & 106,632 & 31,788 & 36 & 8 \\
\hline starling & PASS & 1.72 & 1 & 16,158 & 5,037 & 104 & 2.359 & 106,632 & 16,158 & 36 & 2 \\
\hline eagle & FALC & 1.75 & 7 & 23 & 271 & 205 & 2.941 & 2,444 & 1,189 & 7 & 3 \\
\hline cardinal & PASS & 1.75 & 23 & 0 & 5,037 & 425 & 2.319 & 106,632 & 0 & 36 & 8 \\
\hline hummingbird & APOD & 1.76 & 0 & 1,285 & 399 & 320 & 2.911 & 1,511 & 1,285 & 2 & 1 \\
\hline seagull & CHAR & 1.77 & 2 & 129,395 & 314 & 82 & 2.951 & 204,896 & 129,615 & 3 & 2 \\
\hline woodpecker & PICI & 1.78 & 1 & 1,628 & 376 & 210 & 2.927 & 1,628 & 1,628 & 4 & 3 \\
\hline pigeon & COLU & 1.81 & 4 & 6,618 & 305 & 289 & 2.926 & 10,154 & 10,154 & 3 & 3 \\
\hline thrush & PASS & 1.89 & 2 & 601 & 5,037 & 305 & 2.334 & 106,632 & 5,126 & 36 & 4 \\
\hline falcon & FALC & 1.96 & 4 & 469 & 271 & 58 & 2.959 & 2,444 & 469 & 7 & 1 \\
\hline crow & PASS & 1.97 & 4 & 1,022 & 5,037 & 100 & 2.360 & 106,632 & 4,341 & 36 & 3 \\
\hline hawk & FALC & 1.99 & 15 & 472 & 271 & 205 & 2.941 & 2,444 & 1,189 & 7 & 3 \\
\hline raven & PASS & 2.01 & 0 & 102 & 5,037 & 100 & 2.360 & 106,632 & 4,341 & 36 & 3 \\
\hline goldfinch & PASS & 2.06 & 0 & 3,673 & 5,037 & 425 & 2.319 & 106,632 & 31,788 & 36 & 8 \\
\hline parrot & PSIT & 2.07 & 2 & 0 & 315 & 315 & 2.922 & 0 & 0 & 3 & 3 \\
\hline sandpiper & CHAR & 2.40 & 0 & 58,015 & 314 & 82 & 2.951 & 204,896 & 57,857 & 3 & 1 \\
\hline pheasant & GALL & 2.69 & 3 & 155 & 241 & 165 & 2.950 & 1,389 & 1,389 & 8 & 6 \\
\hline catbird & PASS & 2.72 & 0 & 0 & 5,037 & 30 & 2.368 & 106,632 & 0 & 36 & 2 \\
\hline crane & GRUI & 2.77 & 6 & 0 & 200 & 14 & 2.974 & 20,366 & 0 & 1 & 1 \\
\hline albatross & PROC & 2.80 & 0 & 0 & 93 & 14 & 2.987 & 0 & 0 & 1 & 1 \\
\hline condor & FALC & 2.83 & 0 & 0 & 271 & 6 & 2.966 & 2,444 & 0 & 7 & 2 \\
\hline toucan & PICI & 2.95 & 0 & 0 & 376 & 37 & 2.949 & 1,628 & 0 & 4 & 1 \\
\hline owl & STRI & 2.96 & 4 & 261 & 134 & 123 & 2.968 & 261 & 261 & $i$ & 1 \\
\hline pelican & PELE & 2.98 & 0 & 849 & 54 & 6 & 2.993 & 7,579 & 849 & 1 & 1 \\
\hline goose & ANSE & 3.03 & 7 & 1,129 & 148 & 145 & 2.964 & 201,628 & 201,628 & 3 & 3 \\
\hline vulture & FALC & 3.06 & 4 & 783 & 271 & 6 & 2.966 & 2,444 & 783 & 7 & 2 \\
\hline stork & $\mathrm{CICO}$ & 3.10 & 0 & 0 & 112 & 17 & 2.984 & 1,731 & 0 & 4 & 1 \\
\hline buzzard & FALC & 3.14 & 0 & 694 & 271 & 205 & 2.941 & 2,444 & 1,189 & 7 & 3 \\
\hline swan & ANSE & 3.16 & 4 & 166 & 148 & 145 & 2.964 & 201,628 & 201,628 & 3 & 3 \\
\hline flamingo & $\mathrm{CICO}$ & 3.17 & 0 & 0 & 112 & 6 & 2.986 & 1,731 & 0 & 4 & 1 \\
\hline duck & ANSE & 3.24 & 13 & 200,333 & 148 & 145 & 2.964 & 201,628 & 201,628 & 3 & 3 \\
\hline peacock & GALL & 3.31 & 6 & 0 & 241 & 165 & 2.950 & 1,389 & 0 & 8 & 6 \\
\hline egret & $\mathrm{CICO}$ & 3.39 & 1 & 1,126 & 112 & 58 & 2.979 & 1,731 & 1,722 & 4 & 2 \\
\hline chicken & GALL & 4.02 & 50 & 0 & 241 & 165 & 2.950 & 1,389 & 0 & 8 & 6 \\
\hline turkey & GALL & 4.09 & 10 & 0 & 241 & 2 & 2.970 & 1,389 & 0 & 8 & 1 \\
\hline ostrich & STRU & 4.12 & 0 & 0 & 1 & 1 & 3.000 & 0 & 0 & 1 & 1 \\
\hline titmouse & PASS & 4.35 & 0 & 646 & 5,037 & 65 & 2.364 & 106,632 & 7,617 & 36 & 2 \\
\hline emu & CASU & 4.38 & 0 & 0 & 4 & 1 & 3.000 & 0 & 0 & 1 & 1 \\
\hline penguin & SPHE & 4.53 & 0 & 0 & 17 & 17 & 2.996 & 0 & 0 & 1 & 1 \\
\hline
\end{tabular}

Note-ATF $=$ abstract type frequency. ETF $=$ experiential type frequency. CTF $=$ conceptual type frequency. *The initial four letters of the scientific order name (see Table 1). †The data are from "Cognitive Representations of Semantic Categories" by E. Rosch, 1975, Journal of Experimental Psychology: General, 104, p. 232. Copyright 1975 by the APA. Reprinted by permission. 
Table 3

Intercorrelations of Typicality, Label, Token, and Type Frequencies

\begin{tabular}{lcccccccccc}
\hline & 1 & 2 & 3 & 4 & 5 & 6 & 7 & 8 & 9 & 10 \\
\hline 1 Typicality & - & & & & & & & & & \\
2 Label Frequency & .17 & & & & & & & & \\
3 Token Frequency & $.41 \dagger$ & .08 & & & & & & & \\
4 Order ATF & $.70 \dagger$ & .10 & $.31 *$ & & & & & & \\
5 Family ATF & $.64 \dagger$ & $.29 *$ & $.40 \dagger$ & $.58 \dagger$ & & & & & \\
6 Average Relatedness & $.58 \dagger$ & -.06 & .21 & $.88 \dagger$ & $.40 \dagger$ & & & & & \\
7 Order ETF & $.46 \dagger$ & .20 & $.54 \dagger$ & $.72 \dagger$ & $.41 \dagger$ & $.57 \dagger$ & & & & \\
8 Family ETF & $.35 \dagger$ & .09 & $.96 \dagger$ & $.29 *$ & $.42 \dagger$ & .19 & $.55 \dagger$ & & & \\
9 Order CTF & $.55 \dagger$ & .07 & .21 & $.91 \dagger$ & $.43 \dagger$ & $.91 \dagger$ & $.65 \dagger$ & .21 & & \\
10 Family CTF & $.42 \dagger$ & $.30 *$ & .14 & $.52 \dagger$ & $.69 \dagger$ & $.49 \dagger$ & $.37 \dagger$ & .18 & $.57 \dagger$ & - \\
\hline
\end{tabular}

Note-ATF $=$ abstract type frequency. ETF $=$ experiential type frequency. CTF $=$ conceptual type frequency. ${ }^{*} p \leq .05 . \quad t p \leq .01$.

adding a constant, or "start," of .1 to the variable before taking the logarithm (Mosteller \& Tukey, 1977, p. 83). Furthermore, the measures of typicality and average relatedness have been multiplied by -1 so that all expected correlations are positive.

\section{Results}

Overall correlations. In general, the strongest predictors of typicality are the measures of abstract type frequency. This result remains stable in analyses of different subsets of the data. Table 2 presents data on the birds studied in this paper, sorted from most to least typical. Of the 16 most typical birds, 14 are passerines, or perching birds, the largest order of birds. Table 3 presents Pearson correlations between each pair of the 10 variables described above. Table 4 compares the correlations of all the explanatory variables with typicality in different subsets of the data. Table 4 shows that, using the whole sample (subset ALL, $N=53$ ), typicality is strongly correlated with the measures of abstract type frequency $(.58 \leq r \leq .70)$, moderately correlated with experiential type frequency and conceptual type frequency $(.35 \leq r \leq .55)$, moderately correlated with token frequency $(r=.41)$, and very weakly correlated with the measure of label frequency $(r=.17)$.

Nonpasserine correlations. It appears that the high correlation of abstract type frequency and typicality is not simply an artifact of the contrast between the most typical birds (the passerines) and other birds. One may argue that the fact that the largest order of birds also happens to be regarded as the most typical is simply a coincidence; hence, the correlation between abstract type frequency and typicality would be expected to disappear if passerines were to be eliminated from the analysis. However, the pattern of correlations actually remains quite similar if the analysis is limited to nonpasserines (Table 4, subset NP, $N=32$ ): typicality is strongly correlated with the measures of abstract type frequency (.64 $\leq r \leq .76$ ), moderately to weakly correlated with experiential type frequency and conceptual type frequency $(.19 \leq r \leq .44)$, moderately correlated with token frequency $(r=.46)$, and weakly correlated with the measure of label frequency $(r=.19)$.

Correlations eliminating synonyms. It may also be argued that the weak correlation of typicality with label frequency and the modest correlation of typicality with token

Table 4

Comparison of Correlations with Typicality in Different Subsets

\begin{tabular}{llllllc}
\hline & ALL & NP & P & CLEAN & CAL & PRESENT \\
\hline Label Frequency & .17 & .19 & .34 & .10 & .10 & -.07 \\
Token Frequency & $.41 \dagger$ & $.46 \dagger$ & .14 & $.45 \dagger$ & .03 & -.02 \\
Abstract Type Frequency & & & & & & \\
$\quad$ Order ATF & $.70 \dagger$ & $.65 \dagger$ & & $.71 \dagger$ & $.54 \dagger$ & $.74 \dagger$ \\
$\quad$ Family ATF & $.64 \dagger$ & $.64 \dagger$ & .35 & $.65 \dagger$ & $.36 *$ & .35 \\
$\quad$ Average Relatedness & $.58 \dagger$ & $.76 \dagger$ & .30 & $.60 \dagger$ & $.48 \dagger$ & $.66 \dagger$ \\
Experiential Type Frequency & & & & & & \\
$\quad$ Order ETF & $.46 \dagger$ & .27 & & $.39 \dagger$ & .23 & .29 \\
$\quad$ Family ETF & $.35 \dagger$ & $.44 \dagger$ & .02 & $.46 \dagger$ & -.16 & -.24 \\
Conceptual Type Frequency & & & & & & \\
$\quad$ Order CTF & $.55 \dagger$ & .19 & & $.57 \dagger$ & $.46 \dagger$ & $.65 \dagger$ \\
$\quad$ Family CTF & $.42 \dagger$ & .23 & .25 & $.47 \dagger$ & .25 & .20 \\
\hline
\end{tabular}

Note- ALL $=$ all birds $(N=53), \mathrm{NP}=$ nonpasserine birds $(N=32), \mathrm{P}=$ passerine birds $(N=21)$, CLEAN $=$ birds with unambiguous names $(N=44), \mathrm{CAL}=$ California birds $(N=35)$, PRESENT $=$ California birds with nonzero label frequencies $(N=24)$. ATF $=$ abstract type frequency. ETF $=$ experiential type frequency. CTF $=$ conceptual type frequency. ${ }^{*} p \leq .05 . \quad \dagger p \leq .01$. 
frequency are attributable to problems in the measurement of these variables. However, the correlations of label and token frequency either remain the same or weaken in subsets chosen to correct the measurement problems. For example, certain names of birds in the KuCera and Francis (1967) compilation also have meanings as verbs (e.g., swallow, crane, duck, gull, hawk, crow, dove) or as nouns (e.g., cardinal, crane, lark). However, if these items are eliminated (Table 4 , subset CLEAN, $N=44$ ), the correlation of label frequency with typicality remains small $(r=.10)$.

Correlations eliminating nonlocal birds. Similarly, it may be argued that the correlation of token frequency with typicality would be improved if the analysis were confined to birds actually occurring in the San Francisco Bay Area. After all, the variance in token frequency is depressed with the inclusion of a number of birds with token frequencies of zero. However, as shown in Table 4, the correlation of typicality with token frequency in subset CAL $(N=35)$ is essentially zero $(r=.03)$. The correlation remains low if birds that do not occur on Kučera and Francis's (1967) compilation are also deleted from the analysis (Table 4, subset PRESENT, $N=24 ; r=-.02$ ).

Overall multiple regressions. Multiple regression was used to assess the relative contributions of label, token, and type frequency in explaining typicality, as shown in Tables 5 and 6 . The regressions were run on three subsets of the data to evaluate the robustness of the results. In general, the multiple regressions serve to confirm the findings of the correlation analyses; abstract type frequency is the best predictor of typicality in all three sub- sets. If label and token frequencies are forced into the regression equation first, they together explain $18 \%$ of the total variance using the entire sample (subset ALL). The abstract type frequency measures, order and family ATF, account for an additional $40 \%$ (Table 5.1, subset ALL). The alternative abstract type frequency measure, average relatedness, accounts for an additional $27 \%$ (Table 5.2, subset ALL). Experiential type frequency and conceptual type frequency make relatively smaller contributions, explaining an additional $11 \%$ (Table 5.3, subset ALL) and an additional 22\% (Table 5.4, subset ALL), respectively. However, all four sets of type frequency measures explain more of the total variance in typicality if they are entered first than do label and token frequency if entered first, as shown in Table 6 (subset ALL).

Nonpasserine multiple regressions. If the set of birds used in the analysis is restricted to the nonpasserines (subset NP), the multiple regression of typicality on label, token, and abstract type frequency is little changed. If label and token frequencies are forced into the regression equation first in this subset, they together explain $22 \%$ of the total variance, while the abstract type frequency measures account for an additional $34 \%$ (Table 5.1, subset NP). Average relatedness accounts for an additional $42 \%$ (Table 5.2, subset NP). This indicates that the explanatory power of the abstract type frequency measures is not simply an artifact of the contrast between the typical passerine and the atypical nonpasserine birds. However, experiential type frequency and conceptual type frequency explain no additional variance (Table 5.3, 5.4, col. NP) in this nonpasserine subset.

Table 5

Multiple Regressions of Typicality on Label, Token, and Type Frequency

\begin{tabular}{|c|c|c|c|c|c|c|c|c|c|}
\hline & \multicolumn{3}{|c|}{ ALL } & \multicolumn{3}{|c|}{ NP } & \multicolumn{3}{|c|}{ PRESENT } \\
\hline & $r$ & $r^{2}$ & $\beta$ & $r$ & $r^{2}$ & $\beta$ & $r$ & $r^{2}$ & $\beta$ \\
\hline \multicolumn{10}{|c|}{ 1. Abstract Type Frequency 1} \\
\hline $\begin{array}{l}\text { Label Frequency } \\
\text { Token Frequency } \\
\text { Order ATF } \\
\text { Family ATF }\end{array}$ & $\begin{array}{l}.16 \\
.43 \\
.73 \\
.76\end{array}$ & $\begin{array}{l}.03 \\
.18 \\
.54 \\
.58\end{array}$ & $\begin{array}{l}.02 \\
.14 \\
.48 \dagger \\
.29^{*}\end{array}$ & $\begin{array}{l}.19 \\
.47 \\
.71 \\
.75\end{array}$ & $\begin{array}{l}.04 \\
.22 \\
.50 \\
.56\end{array}$ & $\begin{array}{l}-.19 \\
.20 \\
.43^{*} \\
.34\end{array}$ & $\begin{array}{l}.07 \\
.08 \\
.74 \\
.79\end{array}$ & $\begin{array}{l}.00 \\
.01 \\
.55 \\
.63\end{array}$ & $\begin{array}{l}.04 \\
.05 \\
.72 \dagger \\
.29 *\end{array}$ \\
\hline \multicolumn{10}{|c|}{ 2. Abstract Type Frequency 2} \\
\hline $\begin{array}{l}\text { Label Frequency } \\
\text { Token Frequency } \\
\text { Average Relatedness }\end{array}$ & $\begin{array}{l}.16 \\
.43 \\
.67\end{array}$ & $\begin{array}{l}.03 \\
.18 \\
.45\end{array}$ & $\begin{array}{l}.17 \\
.28 * \\
.52 \dagger\end{array}$ & $\begin{array}{l}.19 \\
.47 \\
.80\end{array}$ & $\begin{array}{l}.04 \\
.22 \\
.64\end{array}$ & $\begin{array}{r}-.12 \\
.25 * \\
.72 \dagger\end{array}$ & $\begin{array}{l}.07 \\
.08 \\
.66\end{array}$ & $\begin{array}{l}.00 \\
.01 \\
.43\end{array}$ & $\begin{array}{l}.02 \\
.05 \\
.66 \dagger\end{array}$ \\
\hline \multicolumn{10}{|c|}{ 3. Experiential Type Frequency } \\
\hline $\begin{array}{l}\text { Label Frequency } \\
\text { Token Frequency } \\
\text { Order ETF } \\
\text { Family ETF }\end{array}$ & $\begin{array}{l}.16 \\
.43 \\
.50 \\
.54\end{array}$ & $\begin{array}{l}.03 \\
.18 \\
.25 \\
.29\end{array}$ & $\begin{array}{c}.08 \\
.89 \\
.35^{*} \\
-.70\end{array}$ & $\begin{array}{l}.19 \\
.47\end{array}$ & $\begin{array}{l}.04 \\
.22\end{array}$ & $\begin{array}{r}.11 \\
.60 \\
-.08 \\
-.12\end{array}$ & $\begin{array}{l}.07 \\
.08 \\
.37 \\
.54\end{array}$ & $\begin{array}{l}.00 \\
.01 \\
.13 \\
.29\end{array}$ & $\begin{array}{r}-.19 \\
.33 \\
.42^{*} \\
-.67^{*}\end{array}$ \\
\hline \multicolumn{10}{|c|}{ 4. Conceptual Type Frequency } \\
\hline $\begin{array}{l}\text { Label Frequency } \\
\text { Token Frequency } \\
\text { Order CTF } \\
\text { Family CTF }\end{array}$ & $\begin{array}{l}.16 \\
.43 \\
.63\end{array}$ & $\begin{array}{l}.03 \\
.18 \\
.40\end{array}$ & $\begin{array}{l}.07 \\
.30^{*} \\
.41 \dagger \\
.12 \\
\end{array}$ & $\begin{array}{l}.19 \\
.47\end{array}$ & $\begin{array}{l}.04 \\
.22\end{array}$ & $\begin{array}{c}-.02 \\
.44 * \\
.10 \\
.10 \\
\end{array}$ & $\begin{array}{l}.07 \\
.08 \\
.66\end{array}$ & $\begin{array}{l}.00 \\
.01 \\
.43\end{array}$ & $\begin{array}{c}.01 \\
.10 \\
.67 \dagger \\
-.01 \\
\end{array}$ \\
\hline
\end{tabular}

Note-Each subtable presents the multiple regression of typicality on label, token, and one of the operationalizations of type frequency. Variables are forced into the regression equations in the order listed. $\quad * p \leq .05 . \quad \dagger p \leq .01$. 
Table 6

Comparison of Variance in Typicality Explained by Type Frequency Measures Versus Label and Token Frequencies

\begin{tabular}{|c|c|c|c|c|c|c|c|c|c|}
\hline & \multicolumn{3}{|c|}{ ALL } & \multicolumn{3}{|c|}{ NP } & \multicolumn{3}{|c|}{ PRESENT } \\
\hline & 1 & 2 & 3 & 1 & 2 & 3 & 1 & 2 & 3 \\
\hline Abstract Type Frequency 1 & .57 & .18 & .58 & .50 & .22 & .56 & .63 & .01 & .63 \\
\hline Abstract Type Frequency 2 & .33 & .18 & .45 & .58 & .22 & .64 & .43 & .01 & .43 \\
\hline Experiential Type Frequency & .23 & .18 & .29 & .19 & .22 & .22 & .20 & .01 & .29 \\
\hline Conceptual Type Frequency & .32 & .18 & .40 & .06 & .22 & .22 & .42 & .01 & .43 \\
\hline
\end{tabular}

Note-Column 1: proportion of total variance $\left(r^{2}\right)$ explained by type frequency variables alone. Column 2: proportion of total variance explained by label and token frequency variables alone. Column 3: total variance explained by all variables.

Multiple regressions eliminating nonlocal birds. If the analysis is restricted to birds that are native to the San Francisco Bay Area and that also appear on the Kučera and Francis (1967) compilation (subset PRESENT), the regression results are even more striking. In this case, even if label and token frequencies are forced into the regression equation first, they together explain only $1 \%$ of the total variance, while the abstract type frequency measures account for an additional $62 \%$ (Table 5.1, subset PRESENT). Average relatedness accounts for an additional 42\% (Table 5.2, subset PRESENT). Experiential type frequency and conceptual type frequency explain an additional 28\% (Table 5.3, subset PRESENT) and an additional 42\% (Table 5.4, subset PRESENT), respectively.

\section{Discussion}

To review, the most powerful and stable predictors of typicality judgments of birds are the measures of abstract type frequency. These results support Rosch and Mervis's (1975) contention that typicality judgments are based on the family resemblances among category members: typical birds are those that are related to the greatest numbers of other birds. As shown in Table 6, order and family ATF explain between $50 \%$ and $63 \%$ of the total variance, whereas average relatedness, the alternate measure of abstract type frequency, explains between 33\% and $43 \%$ of the variance across different subsets. The other operationalizations of type frequency, experiential and conceptual, predict either less well or less consistently, explaining between $19 \%$ and $23 \%$ and between $6 \%$ and $42 \%$ of the variance, respectively.

In contrast, the familiarity measures, label and token frequency, explain between only $18 \%$ and $22 \%$ of the variance. Even these modest correlations virtually disappear when the sample is restricted to birds native to the San Francisco Bay Area that appear in the Kučera and Francis (1967) listings. This indicates that much of the apparent explanatory power of the label and token frequency measures in the overall analysis stems from the contrast between birds that the individuals encounter either in books or in the environment and those that they do not; the former are judged as more typical than the latter. This is the response bias referred to above (Malt \& Smith, 1982). Among birds encountered both in the natural world and in the written word, variation in the number of instances of the birds has no effect on typicality judgments.
The correlation of typicality with abstract type frequency compares favorably with the correlations of typicality with the explanatory variables used by other investigators. Again, the multiple $r$ of typicality with abstract type frequency was .76 for the complete inventory (subset ALL) and .79 for the familiar California birds (subset PRESENT). Ashcraft (1978) reported a correlation of .45 between typicality and mean number of properties generated (NP). Malt and Smith (1982) found a correlation of .68 between NP and typicality in birds, which dropped to .60 when unfamiliar exemplars were removed. Hampton and Gardiner (1983) found an average raw correlation of .54 between rated familiarity and rated typicality across all categories studied, and a correlation of .58 between familiarity and typicality for birds. For common taxonomic categories, Barsalou (1985) found average raw correlations of .63 between typicality and central tendency, .47 between typicality and frequency of instantiation, and .46 between typicality and ideals, which became $.71, .36$, and .45 , respectively, when the other variables were partialled out. For birds alone, the partial correlations are $.75, .42$, and .78 , respectively. Schwanenflugel and Rey (1986) reported correlations between rated familiarity and rated typicality of .48 (English speakers) and .47 (Spanish speakers) across all categories studied, and correlations of .12 (English speakers) and 68 (Spanish speakers) between familiarity and typicality for birds. Because the measures of abstract type frequency used here are not based on subjects' reports, they are not liable to the typicality confounds that may affect NP and the ratings of familiarity and frequency of instantiation, as discussed above.

It may be surprising that size of order and family of birds should be so strongly correlated with typicality, since it is doubtful that Rosch's (1975b) subjects knew the scientific classification of the birds, given the general biological ignorance of urban Americans (Berlin, 1972, pp. 83-84; Dougherty, 1978). Apparently subjects were responding solely to the pattern of similarity among the birds; the subjects may not know much about science, but they at least know which birds are alike. It is as though individuals keep cumulative mental inventories of the types of birds they have encountered and accordingly adjust their sense of the modal characteristics of the superordinate category bird. To emphasize, it is the cumulative inventory of types, not tokens, encountered that seems 
to be the prime determinant of typicality judgments. However, since token-rich types are more likely to be encountered than token-poor types, token frequency would be expected to have a moderate correlation with typicality over birds in general, as indeed it does $(r=.41)$. Again, this relationship disappears when the sample is limited to birds likely to be encountered in the written or natural environment $(r=-.02)$.

\section{EXPERIMENT 2}

The high correlation of abstract type frequency with typicality should be interpreted as strong support for Rosch and Mervis's (1975) account of the structural basis of typicality effects. But, as stated above, typicality effects are related to a variety of aspects of perception and the organization of semantic memory. If typicality effects have a structural basis, then there should be other sorts of evidence that subjects are responding to that structure beyond their judgments of which items are most typical. In other words, subjects should respond to the passerines in other ways that reflect the passerines' structural position as most similar to other birds. Experiment 2 explored the difference in subjects' patterns of discrimination and identification of passerine versus nonpasserine bird specimens. A constant set of South American bird specimens, including both passerine and nonpasserine species, was shown to culturally diverse groups of subjects: Aguaruna and Huambisa Jivaro of the Peruvian tropical forest, U.S. college students, and an ornithologist. Judgments of the similarities of the specimens were elicited from the diverse groups in a variety of ways. The first three findings of this experiment were reported in Boster (1987), Boster et al. (1986), and Boster and D'Andrade (in press); the last four are reported here for the first time.

\section{Method}

In the Jivaroan ornithological research, adult Aguaruna and Huambisa subjects were asked to identify prepared bird specimens. The degree to which specimens receive identical identification responses was gauged by measuring the increase in randomness when the responses to specimens are pooled. If the responses are identical, there is no increase in randomness; if there is no overlap of the responses, the increase in randomness is at a maximum. This measure, referred to as specimen overlap, is the complement of Pielou's measure of niche overlap (Pielou, 1977, pp. 306-307). Further details of the methods used are reported in Berlin, Boster, and O'Neill (1981) and Boster et al. (1986).

In the U.S. research (Boster, 1987), University of Kentucky students were asked to participate in two specimen-sorting experiments, a grouping experiment and a dividing experiment. The subjects were screened to ensure that they had no formal training in zoology or familiarity with these South American birds. In the grouping experiment, the subjects were asked to arrange specimens into groups on the basis of their overall similarity. Each subject performed this task separately on subsets of 40 passerine specimens and 40 nonpasserine specimens. The judged similarity of each pair of specimens was measured by counting how often the pair was placed in the same group. In the dividing experiment, the subjects were first asked to place the specimens into groups on the basis of their overall similarity. The subjects were then asked to divide whichever group they thought most heterogeneous into two coherent subgroups. The subject continued to divide groups until all specimens were separated. Next, the subject's initial groups were restored and the subject was asked to merge the most similar pair of groups. The subject continued to merge groups until all specimens were merged. Each subject performed the task separately on subsets of 15 passerine and 15 nonpasserine specimens. The judged similarity of each pair of specimens was measured by counting the rank order in which they were split apart. Further details of the methods used are reported in Boster (1987).

The degree of biological similarity, or taxonomic distance, between bird specimens was computed as described in Experiment 1. The ornithologist who identified the specimens also performed the dividing experiment, using species names on index cards as stimuli rather than specimens. These judgments broke ties in the taxonomic distances, disambiguating, for example, which species in a genus are most similar. Again, the judged similarity of species was measured by counting the rank order in which they were split apart (Boster, 1987).

\section{Results}

To reiterate, the major result of Experiment 1 is that typicality ratings of birds are best explained by the $a b$ stract similarity of the birds themselves, as measured by the number of species in the birds' order and family. In particular, members of the largest order of birds, the passerines, are overwhelmingly regarded as the most typical. There are seven findings of this second study that are relevant to this result.

First, the culturally diverse subject groups recognized substantially similar patterns of resemblance among a collection of South American bird specimens; the matrices of item-by-item similarity derived from their responses were highly correlated $(.34 \leq r \leq .94)$. The natural order appears to be perceived by human observers in much the same way, regardless of cultural background (Boster et al., 1986; Boster, 1987).

Second, the agreement among subject groups is not simply due to the correlational structure of the stimuli; there is evidence that the different groups of subjects shared a strategy of selecting those attributes of a collection of specimens that yield the most informative classification (Boster \& D'Andrade, in press).

Third, subject groups agreed more strongly on the similarities of nonpasserine birds than on the similarities of the passerines (Boster, 1987; Boster et al., 1986).

Fourth, in spite of the fact that the U.S. college students had not seen these South American bird species before and most did not have names for any of them (some subjects did recognize the woodpeckers and the toucans among the nonpasserines), most of these subjects who were queried regarded the passerines as more like their idea of typical birds (proportion $=92 \%, N=13$, binomial test $p=.006$ ). If typicality judgments were simply a product of familiarity with verbal categories, the subjects in the U.S. experiments would not consistently have picked one or another of the novel specimens as more typical examples of birds.

Fifth, when asked, the U.S. college students stated that they found sorting the passerines to be more difficult than 
sorting the nonpasserines (proportion $=84 \%, N=19$, binomial test $p=.012$ ).

Sixth, the Jivaroan subjects agreed with each other much more often on the names of the nonpasserine specimens than they did on the passerines. The average proportional uncertainty (Berlin et al., 1981) in identification of the nonpasserine specimens was $.16(S D=.13, N=169)$, whereas the average proportional uncertainty on the passerine specimens was $.43(S D=.23, N=299)$. The probability of a difference this great is less than 1 in 1,000 $(t=513.9)$.

Seventh, the Jivaroan subjects appear to have attempted to discriminate the passerine specimens more finely than the nonpasserines, thereby setting themselves a harder task with this group of specimens: they merged genera and species of nonpasserines and distinguished species of passerines. Table 7 documents the difference between the passerine and nonpasserine specimens in the level of correspondence of folk categories to scientific taxa. It shows the mean and standard deviation of the measure of specimen overlap for each level of taxonomic difference between the specimens. A specimen overlap value of 1 would indicate that there was no overlap between lists of names, and a value of 0 would indicate that the two lists of names were identical. The differences in mean specimen overlap between the levels of taxonomic distance reflect differences in the average level of mapping of folk categories to scientific taxa. The fact that the means of specimen overlap at the ordinal and familial ranks are all above .9 indicates that the Jivaroan subjects kept both the passerines and the nonpasserines distinct at these ranks; if two specimens are in different families or orders, it is very unlikely that they would have been named the same. Below the rank of the family, the passerines and the nonpasserines are markedly different. At the species and genus ranks, it appears that the subjects merged the nonpasserines more than the passerines. Although the effect is stronger for the Aguaruna than for the Huambisa, both groups seemed to distinguish between nonpasserines at the genus or family rank but to distinguish between passerines at the species rank.

\section{Discussion}

The last finding is the most surprising. I had expected that subjects would expend roughly equal effort in classifying all groups of birds and that subjects would recognize large categories in collections of organisms that show subtle internal differentiation and small categories when that differentiation is striking. Yet the subjects appear to have worked doubly hard at difficult discriminations, attending more closely to the subtly differentiated passerines than the more easily distinguished nonpasserines.

The factors of cultural importance and perceptual salience, which often explain cases in which folk classifiers pay closer attention to one group of organisms than another (Berlin et al., 1981), cannot explain this case. The nonpasserines include the culturally most important game species (Cracidae: curassows and guans), pets (Psittacidae: parrots and macaws), and ornamental feather sources (Ramphastidae: toucans). They are also, in general, larger and more perceptually salient than the passerines. It also does not appear that individual passerine species are observed more frequently on average than nonpasserine species. By these criteria, we would expect that the nonpasserines would be more carefully attended to than the passerines, instead of the other way around.

The Jivaro are not alone in oversplitting the passerines; they are joined by both American English speakers (as mentioned above) and by scientific ornithologists. Van Tyne and Berger (1959) argued that if the same standards of classification were maintained for passerines as for the nonpasserine families, avian taxonomists would probably place all passerines in one family. But because passerines make up more than half of all bird species, taxonomists have found it expedient to divide them into between 44 and 53 families (1959, pp. 593-594).

\section{GENERAL DISCUSSION}

To review, Experiment 1 supported Rosch and Mervis's (1975) conclusion that resemblance to other category members, rather than familiarity, best predicts subjects' typicality judgments. It showed that subjects generally

Table 7

Means and Standard Deviations of Specimen Overlap in the Jivaroan Bird Identification Experiments at Different Taxonomic Distances

\begin{tabular}{|c|c|c|c|c|c|c|}
\hline & \multicolumn{3}{|c|}{ Aguaruna } & \multicolumn{3}{|c|}{ Huambisa } \\
\hline & $M$ & $S D$ & $N$ & $M$ & $S D$ & $N$ \\
\hline \multicolumn{7}{|c|}{ Nonpasserines } \\
\hline Order & .98 & .06 & 1480 & .98 & .07 & 2077 \\
\hline Family & .97 & .11 & 247 & .97 & .13 & 261 \\
\hline Genus & .54 & .38 & 88 & .48 & .42 & 127 \\
\hline Species & .10 & .12 & 15 & .39 & .34 & 20 \\
\hline \multicolumn{7}{|c|}{ Passerines } \\
\hline Family & .95 & .09 & 4213 & .91 & .12 & 5976 \\
\hline Genus & .84 & .21 & 495 & .77 & .20 & 635 \\
\hline Species & .51 & .31 & 45 & .46 & .23 & 59 \\
\hline
\end{tabular}


regard members of the largest order of birds, the passerines, as most typical. Experiment 2 placed the typicality judgments in the context of other kinds of subject responses to the two sets of birds. As reported in earlier work (Boster, 1987; Boster et al., 1986; Boster \& D'Andrade, in press), there is evidence that diverse groups of subjects use similar strategies of selecting attributes of bird specimens (finding 2) to come to similar conclusions about the pattern of resemblance among them (finding 1). Experiment 2 presents evidence that the different groups appear to find the identification and similarity judgment tasks among the passerines more difficult than among the nonpasserines (findings 5 and 6). The U.S. subjects also regarded the passerine set of specimens as the most typical (finding 4). There is also stronger agreement among alternate classification systems on the nonpasserines than on the passerines (finding 3). But, paradoxically, both the Jivaroans and the scientific ornithologists apparently attempt to discriminate the typical passerine birds more finely than the atypical nonpasserines (finding 7).

\section{Geometric Similarity Space Models}

Subjects' differential response to passerines and nonpasserines, whether in typicality judgments or in similarity judgment tasks, is consistent with geometric similarity space models developed by Hunn (1976), LeGendre and Rogers (1972), and Krumhansl (1978).

Hunn's model. In Hunn's model, two parameters determine whether a collection of organisms will be recognized as a discrete category: the internal heterogeneity of a potential category and the minimum external gap, the smallest gap between the potential category and another category. The higher the ratio of minimum external gap to internal heterogeneity, the greater the likelihood that the group will be recognized as a discrete class (Hunn, 1976, p. 519). LeGendre and Rogers (1972) proposed a very similar model as a prescription of how numerical taxonomists should classify organisms, rather than as a description of how the folk classify. Using this model, nonpasserines would be described as being highly structured and having a high ratio of external differences to internal differences; they would be perceived by the diverse observers as a dispersed set of tightly aggregated clumps. In contrast, the passerines would be described as weakly structured with a low ratio of external differences to internal differences; they would be perceived as having a more or less continuous distribution through the similarity space.

Krumhansl's model. Krumhansl (1978) described a density-dependent geometric similarity model as a way of answering Tversky's (1977) criticisms of the application of geometric models to similarity data. In her model, the distance between points is dependent on the density of surrounding points: within dense subregions of the stimulus range, finer distinctions are made than within relatively less dense subregions. She described her model as consistent with earlier work that shows that stimuli with the fewest errors in a learning paradigm were those on the extremes of variation within the stimulus set (Attneave, 1950) or those with relatively few neighboring points in a same-different judgment task (Rothkopf, 1957; Shepard, 1963). She described her model as consistent also with the finding that discrimination reaction time increases as the similiarity between objects in the domain increases (Bindra, Donderi, \& Nishisato, 1968; Crossman, 1955; Smith, 1968). Thus, dense regions of similarity spaces demand finer distinctions, with the cost of more errors and more work. She used this distance-density model to provide an alternative account of a number of phenomena cited by Tversky (1977) in his critique of geometric models, including asymmetries in similarity judgments, violations of the triangle inequality, context differences in diagnostic features, and differences between similarity and difference judgments.

Krumhansl's (1978) model also provides an explanation of why subjects should attempt to discriminate dense regions of the similarity space more finely than sparse regions (finding 7). Because perceived distance is dependent on the density of neighboring points, two items in a relatively sparse region should be seen as more similar than a pair of points differing by an equivalent amount in a more dense region of the space $(1978$, p. 458). It also would exaggerate the appearance of clumping in the sparse regions of the space. Thus her model provides an explanation of why subjects should work harder to make finer discriminations in dense regions of the space. Because items in dense subregions are more similar to other items than those in sparse subregions, the dense subregions will also be regarded as the prototypical examples of the domain (Rosch \& Mervis, 1975).

A hybrid similarity space model. Hunn's (1976) and Krumhansl's (1978) models provide complementary refinements of a geometric similarity model that answer Tversky's (1977) criticisms. Using a hybrid of their models, the perceptual task that confronts the subjects in these similarity judgment tasks would be described as follows. The perceptual gaps between species, genera, and families of nonpasserines are much greater than those separating corresponding taxa of passerines. Because the stimuli are sparsely distributed through the similarity space, subjects perceive a shrinking of the distances between neighboring points; they attend to the great gulfs separating categories and are less likely to be bothered by the internal diversity within categories. The subjects appear to be grouping on the basis of the differences between the categories rather than attempting to isolate internally consistent groupings of organisms. However, when the birds are much more similar to each other, as in the case of the passerines, the subjects are less likely to look for perceptual gaps between groups of organisms and to base their categories on the internal similiarities of specimens in the same species: the density of the stimuli exaggerates their perceived distance. Informants base their classifications on the largest discontinuities in the pattern of resemblances between the organisms. If confronted with a large collection of organisms that are distinguished 
by subtle attributes, subjects are likely to form small categories and are not likely to agree often with each other. If confronted with a collection of organisms that are not very similar to each other but are extremely different from other organisms, the subjects are likely to form large, well-agreed-on categories, capturing the collection's difference from other organisms (its "strangeness") rather than its internal coherence. Hummingbird species, for example, do differ considerably from one another, but, because they are so strange as a group, the internal differences appear less important. Thus, the Jivaro usually identify all hummingbirds as members of the same category. Birds that look more like typical birds, such as the passerines, are likely to be more closely studied. It is because subjects are identifying species in the same genus of nonpasserines with the same lists of names, yet are sharply distinguishing them at the family and order ranks, that the correspondence between alternative classifications is so much stronger for nonpasserines than for passerines (finding 3).

\section{Conclusions}

This study presented ornithological evidence in support of Rosch and Mervis's (1975) explanation of typicality as a function of family resemblances between category members. Typical birds are those that are members of large orders and families, not those whose names are read most often or that are seen most frequently: frequency of types similar to an item is more important than either frequency of labels or tokens in accounting for typicality.

I believe this study demonstrated the value of looking at the real world origins of category structure; it shows that the biological taxonomies created by scientists can be useful in representing the similarity among types recognized by the rest of us, thereby providing investigators with relatively objective predictors of typicality effects. With the growing use of natural stimulus materials in cognitive research, there is a corresponding need to take advantage of our best understanding of that structure, an understanding that can often be provided by the natural sciences.

This study also showed the relationship between typicality effects and a number of distinct aspects of the internal structure of a natural category. Earlier reports (Boster, 1987; Boster et al., 1986) presented evidence that there is less agreement between alternate classification systems on the pattern of similarities among the most typical birds (passerines) than among less typical birds (nonpasserines). Here, it was shown that subjects also make finer discriminations of passerines than of nonpasserines, yet disagree more in identifying passerines and report greater difficulty in judging the similarities among passerines. A single model can explain these effects: Passerines appear to be densely and continuously spread throughout bird similarity space, whereas nonpasserines are more sparsely distributed, leading to the choice of the passerines as at once more typical and more difficult to categorize than nonpasserines. The model serves to fur- ther articulate Rosch and Mervis's (1975) idea that typicality effects are a consequence of internal category structure, a structure that in this case is the product of biological evolution.

\section{REFERENCES}

Ashcraft, M. H. (1978). Property norms for typical and atypical items from 17 categories: A description and discussion. Memory \& Cognition, 6, 227-232.

Attneave, F. (1950). Dimensions of similarity. American Journal of Psychology, 63, 516-556.

Barsalou, L. W. (1985). Ideals, central tendency, and frequency of instantiation as determinants of graded structure in categories. Journal of Experimental Psychology: Learning, Memory, \& Cognition, 11, 629-654.

Battig, W. R., Montague, W. E. (1969). Category norms for verbal items in 56 categories: A replication and extension of the Connec ticut category norms. Joumal of Experimental Psychology Monograph, 80, (3, Pt. 2).

BERLIN, B. (1972). Speculations on the growth of ethnobotanical nomenclature. Language in Society, 1, 51-86.

BerLIN, B. (1973). Folk systematics in relation to biological classification and nomenclature. Annual Review of Ecology \& Systematics, 4 , 259-271.

Berlin, B., Boster, J., \& O'Neill, J. (1981). The perceptual bases of ethnobiological classification: Evidence from Aguaruna Jivaro ornithology. Journal of Ethnobiology, 1, 95-108.

Berlin, B., Breedlove, D., \& Raven, P. (1973). General principles of classification and nomenclature in folk biology. American Anthropologist, 75, 214-242.

Bindra, D., Donderi, D. C., \& Nishisato, S. (1968). Decision latencies of "same" and "different" judgments. Perception \& Psychophysics, 3, 121-130.

Boster, J. (1987). Agreement among biological classification systems is not dependent on cultural transmission. American Anthropologist, 89, 914-920.

Boster, J., Berlin, B., \& O'Neill, J. (1986). The correspondence of Jivaroan to scientific ornithology. American Anthropologist, 88, 569-583.

Boster, J., \& D'ANDrade, R. (in press). Natural and human sources of cross-cultural agreement in ornithological classification. American Anthropologist.

Crossman, E. R. F. W. (1955). The measurement of discriminability. Quarterly Review of Experimental Psychology, 7, 176-195.

Diamond, J. (1966). Classification system of primitive people. Science, 151, $1102-1104$.

DOUgherTY, J. (1978). Salience and relativity in classification. American Ethnologist, 5, 66-80.

Glass, A. L., \& MEany, P. J. (1978). Evidence for two kinds of lowtypical instances in a categorization task. Memory \& Cognition, 6 , $622-628$.

Hampton, J. A. (1979). Polymorphous concepts in semantic memory. Journal of Verbal Learning \& Verbal Behavior, 18, 441-461.

Hampton, J. A., \& Gardiner, M. M. (1983). Measures of internal category structure: A correlational analysis of normative data. British Journal of Psychology, 74, 491-516.

HunN, E. (1975). A measure of the degree of correspondence of folk to scientific classification. American Ethnologist, 2, 309-327.

HuNN, E. (1976). Toward a perceptual model of folk biological classification. American Ethnologist, 3, 508-524.

KrumhansL, C. L. (1978). Conceming the applicability of geometric models to similarity data: The interrelationship between similarity and spatial density. Psychological Review, 85, 445-463.

KuCERA, H., \& Francis, W. N. (1967). Computational analysis of present-day American English. Providence, RI: Brown University Press.

LAKOFF, G. (1973). Hedges: A study in meaning criteria and the logic of fuzzy concepts. Journal of Philosophical Logic, 2, 458-508.

LeGendre, P., \& Rogers, D. J. (1972). Characters and clustering in 
taxonomy: A synthesis of two taximetric procedures. Taxon, 21, 567-606.

MALT, B. C., \& SMITH, E. E. (1982). The role of similarity in determining typicality. Memory \& Cognition, 10, 69-75.

Malt, B. C., \& SMITH, E. E. (1984). Correlated properties in natural categories. Journal of Verbal Leaming \& Verbal Behavior, 23. 250-269.

MCCLoskey, M. (1980). The stimulus familiarity problem in semantic memory research. Journal of Verbal Learning \& Verbal Behavior, 19, 485-502.

McFarland, C. E., Duncan, E. M., \& Kellas, G. (1978). Isolating the typicality effect in semantic memory. Quarterly Journal of Experimental Psychology, 30, 251-262.

Mervis, C. B., Catlun, J., Rosch, E. (1976). Relationships among goodness of example, category norms, and word frequency. Bulletin of the Psychonomic Society, 7, 283-284.

MERVIs, C. B., \& RosCH, E. (1981). Categorization of natural objects. Annual Review of Psychology, 32, 89-115.

Mosteller, F., \& TUKEY, J. W. (1977). Data analysis and regression: A second course in statistics. Menlo Park, CA: Addison-Wesley.

National Audubon Society (1983). Christmas bird counts nos. 1-1452. American Birds, 37, 409-792.

Pielou, E. C. (1977). Mathematical ecology. New York: Wiley.

RIPS, L. J. (1975). Inductive judgments about natural categories. Journal of Verbal Learning \& Verbal Behavior, 14, 665-681.

Rirs, L. J., Shoben, E. J., \& SMITH, E. E. (1973). Semantic distance and the verification of sentences. Journal of Verbal Learning \& Verbal Behavior, 12, 1-20.

Rosch, E. (1973). On the internal structure of perceptual and semantic categories. In T. E. Moore (Ed.), Cognitive development and the acquisition of language (pp. 111-144). New York: Academic Press.

Rosch, E. (1975a). Cognitive reference points. Cognitive Psychology, 7, 532-547.

Rosch, E. (1975b). Cognitive representations of semantic categories. Journal of Experimental Psychology: General, 104, 192-233.

Rosch, E. (1978). Principles of categorization. In E. Rosch \& B. B. Lloyd (Eds.), Cognition and Categorization (pp. 27-48). Hillsdale, NJ: Erlbaum.

Rosch, E., \& Mervis, C. B. (1975). Family resemblances: Studies in the internal structure of categories. Cognitive Psychology, 7, 573-605.

Rosch, E., Simpson, C., \& MILLER, R. S. (1976). Structural basis of typicality effects. Journal of Experimental Psychology: Human Perception \& Performance, 2, 491-502.

Roth, E., MERvis, C. B. (1983). Fuzzy set theory and class inclu- sion relations in semantic categories. Journal of Verbal Learning \& Verbal Behavior, 22, 509-525.

RoTHKOPF, E. Z. (1957). A measure of stimulus similarity and errors in some paired-associate learning tasks. Journal of Experimental Psychology, 53, 94-101.

Schustack, M. W., ANDERson, J. R. (1979). Effects of prior knowledge on memory for new information. Journal of Verbal Learning \& Verbal Behavior, 18, 565-583.

SChWANEnflugel, P. J., ReY, M. (1986). The relationship between category typicality and concept familiarity: Evidence from Spanishand English-speaking monolinguals. Memory \& Cognition, 14, 150-163.

SHEPARD, R. N. (1963). Analysis of proximities as a technique for the study of information processing in man. Human Factors, 5, 33-48.

SMITH, E. E. (1968). Choice reaction time: An analysis of the major theoretical positions. Psychological Bulletin, 69, 77-110.

Smith, E. E., Shoben, E. J., \& Rips, L. J. (1974). Structure and process in semantic memory: A featural model for semantic decisions. Psychological Review, 81, 214-241.

TVERSKY, A. (1977). Features of similarity. Psychological Review, 84, 327-352.

Tversky, A., \& Gati, I. (1978). Studies of similarity. In E. Rosch \& B. B. Lloyd (Eds.), Cognition and categorization (pp. 79-98). Hillsdale, NJ: Erlbaum.

TVERSKY, A., \& KAHNEMANN, D. (1974). Judgment under uncertainty: Heuristics and biases. Science, 185, 1124-1131.

VAN TYNE, J., \& BerGer, A. (1959). Fundamentals of ornithology. New York: Wiley.

Wallace, G. J., \& Mahan, H. D. (1975). An introduction to ornithology (3rd ed.). New York: MacMillan.

\section{NOTE}

1. Order and family refer to taxonomic ranks at different levels of inclusiveness in the scientific classification of organisms. For example, in order of decreasing inclusiveness, human beings are members of the phylum Chordata, the class Mammalia, the order Primates, the family Hominidae, the genus Homo, and the species sapiens. In contrast, American robins are members of the phylum Chordata, the class Aves, the order Passeriformes, the family Turdidae, the genus Turdus, and the species migratorius.

(Manuscript received July 29, 1985; revision accepted for publication October $30,1987$. 